\title{
A Comprehensive Survey on Image Modality Based Computerized Dry Eye Disease Detection Techniques
}

\author{
Aditi Haresh Vyas*, Mayuri A. Mehta \\ Department of Computer Engineering, Sarvajanik College of Engineering and Technology, Surat, 395001, Gujarat, India
}

\begin{tabular}{l} 
A R T I C L E I N F O \\
\hline Article history: \\
Received: 08 February, 2020 \\
Accepted: 25 March, 2020 \\
Online: 20 April, 2020
\end{tabular}

Keywords:

Dry Eye

Disease detection

Tear film breakup

Lipid layer pattern

Image Processing

Deep learning

\begin{abstract}
A B S T R A C T
Dry Eye Disease (DED) is one of the commonly occurring chronic disease today, affecting the vision of eye. It causes severe discomfort in eye, visual disturbance and blurred vision impacting the quality of life of patients. Due to recent advancements in Artificial Intelligence (AI) and rapid progress of analytics techniques, several image modality based computerized DED detection techniques are available in literature. These techniques transform image data into real and actionable insights and thus, provide new understanding and ways for better and quicker treatment. In addition, they assist ophthalmologist to diagnose dry eye disease precisely as well as to reduce the cost of healthcare. In this paper, we present a review on computerized DED detection techniques covering all available techniques. In addition, we present a parametric evaluation of these techniques based on our identified set of parameters. Though surveys on clinical DED detection techniques are available, this is the first attempt in literature to log down all computerized DED detection techniques at one place. Our survey will assist researchers and ophthalmologists to understand various technological advancements in the field of DED detection. As a little amount of work has been done in the field of automatizing dry eye disease detection, the field provides plenty of research opportunities to develop an automated efficient DED detection technique.
\end{abstract}

\section{Introduction}

Eye is a sensory organ of human body and is responsible for vision. Humans receive information of their surroundings through eyes. A transparent structure situated in front of the eye is referred as cornea [1-3]. In order to keep eyes healthy, cornea should be kept moist. A tear film located on the cornea helps to fulfill this need [2-4]. Tear film is a three layered structure having lipid layer on the outer surface, aqueous layer in middle and mucous layer in the inner portion of the cornea. It has several functions such as providing nourishment to the cornea, lubricating corneal surface and maintaining moisture of the eye. Certain factors such as prolonged use of electronic gadgets, old age, environmental conditions, medication, smoking habits and use of contact lens can disturb the tear film balance and can lead to evaporation of moisture from tear film causing dry eye disease [5-8].

Dry eye disease is a common and widespread eye disease in the world today. It is a growing health problem that affects significant percentage of population in the world [2-3, 7]. It occurs due to instability in tear film, reduction in tear production or

\footnotetext{
*Aditi H. Vyas, Email: aditi.vyas.9@gmail.com
}

abnormality in tear producing glands. Symptoms of dry eye disease include blurred vision, burning sensation, sore and itchy eye, foreign body sensation and photophobia [3, 5-6]. If DED is left untreated, it can cause infection, corneal ulcer or blindness [911]. Clinical diagnosis of dry eye is a difficult task because it occurs due to different factors. A clinician sometimes requires multiple tests or repetitive tests for proper diagnosis. Some of the clinical tests used for diagnosis of dry eye are dry eye questionnaire such as Ocular Surface Disease Index (OSDI) [12] and Mc Monnies [13], tear film breakup time test, schirmer test and meibomain secretion scoring [4-6, 9, 11-14].

The major drawbacks of clinical are as follows: 1) Each clinical test takes long time to diagnose dry eye as it is performed manually. 2) Diagnosis by clinical test is subjective in nature 3) Accurate severity level of dry eye disease is not identified due to subjectivity in diagnosis and 4) Medication may be prescribed for incorrect period on the basis of inaccurate severity level. It was observed by research community that the computerization of clinical tests will help ophthalmologist and optometrist to bring objectivity and to increase accuracy of the diagnosis. Moreover, computerization makes diagnosis faster which in turn saves time 


\section{A.H. Vyas et al. / Advances in Science, Technology and Engineering Systems Journal Vol. 5, No. 2, 748-756 (2020)}

of ophthalmologist and gives him more time for counselling of patients. Several DED detection techniques have been proposed in literature.

In this paper, we summarize them along with corresponding clinical tests. Based on our study, we classify the techniques into following three major categories subject to the approach used to identify the dry eye disease: 1) Techniques based on tear film stability [15-25], 2) Techniques based on blink rate detection [26] and 3) Techniques based on amount of tear produced [27]. DED detection techniques based on tear film stability further differ from each other with respect to imaging modality. Hence, based on imaging modality used, we further classify them into three subcategories: techniques using fluorescein tear film video [1522], techniques using lipid layer interference patterns [23-24] and techniques using thermal infrared images [25]. From our rigorous study on DED detection techniques, we have identified several parameters to evaluate them. We then present a comprehensive and comparative evaluation of these techniques based on identified parameters. To the best of our knowledge, this is the first attempt to note down all image modality based computerized DED detection techniques at one place. The objective of this survey is to discuss the some clinical tests and their corresponding computerized DED detection techniques as well as to emphasize the potential of DED detection techniques in the domain of healthcare. It has been observed that a little amount of work has been done in the field of automatizing dry eye disease detection and hence, it provides an ample amount of research opportunities in this field. The researchers may come up with an efficient new DED detection technique corresponding to any of the commonly adopted clinical tests.

The rest of this paper is organised as follows: Section II introduces the key concepts related to dry eye disease to understand its background. In addition, various clinical tests for which computerized techniques have been proposed are discussed in this section. Section III describes the proposed taxonomy of computerized DED detection techniques along with their detailed discussion. Section IV presents comparative analysis of DED detection techniques. In particular, the parametric evaluation of DED detection techniques based on identified parameters and summary of these techniques are presented in this section. Finally, conclusions and future work are specified in section $\mathrm{V}$.

\section{Dry Eye Disease and its Clinical Diagnosis}

As shown in Figure 1, human eye is divided into two major parts: anterior segment and posterior segment [1]. Anterior segment mainly consists of iris, cornea, lens, pupil, anterior chamber and ciliary muscle. Posterior segment consists of sclera, retina, choroid, fovea, optic nerve and retinal blood vessels. Many diseases manifests themselves in eye such as corneal ulcer, diabetic retinopathy, age related macular degeneration, glaucoma, cataract, dry eye and so on. Amongst these diseases, dry eye is the most commonly occurring disease caused due to instable tear film on cornea.

Dry eye also known as keratoconjunctivitis sicca is defined as a multi-factorial disease characterized by unstable tear film causing a variety of symptoms and/or visual impairment, potentially accompanied by ocular surface damage [2-3]. It is classified into two major categories: aqueous deficient dry eye and evaporative dry eye. Aqueous deficient dry eye refers to low production of tears. Evaporative dry eye refers to excess evaporation of tears from the eye. Both the categories show similar symptoms and may co-exist.

As diagnosis of dry eye disease is a difficult task, ophthalmologist sometimes requires performing different diagnosis tests to diagnose dry eye. Ophthalmologist starts diagnostic procedure by asking patient the history and symptoms related to dry eye disease. Predefined symptom questionnaires such as OSDI, Mc Monnies and Dry Eye Questionnaire are available to know the history and symptoms [12-13]. The questionnaire provides a score that serves as a basis to identify DED. A low score indicates normal eye and a high score indicates possibility of dry eye. However, ophthalmologist cannot completely rely upon questionnaire and hence, questionnaire procedure is often followed by different clinical tests.

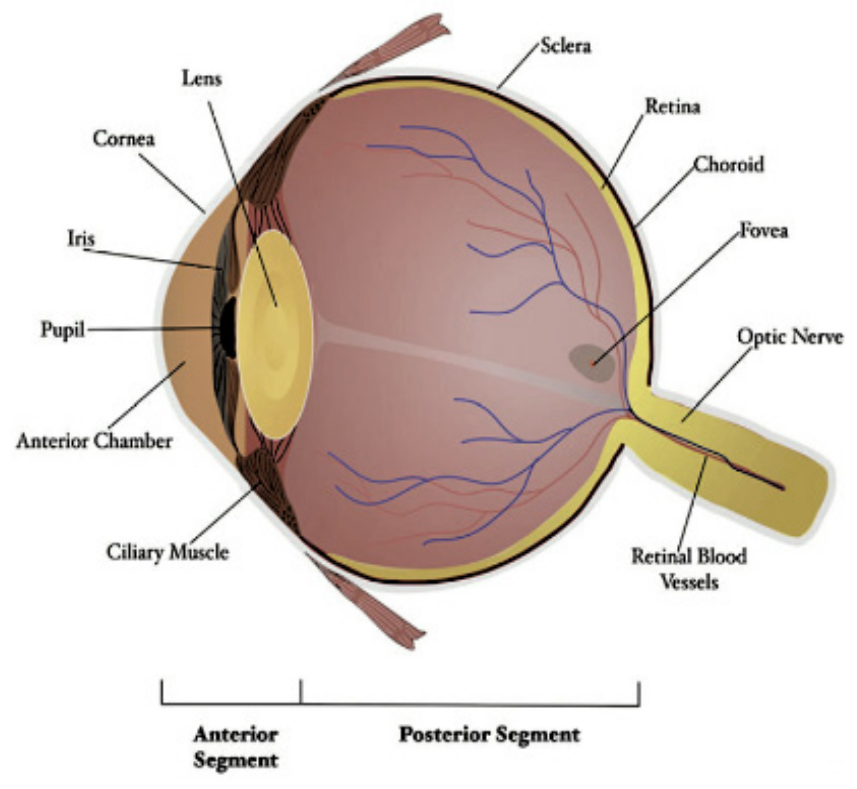

Figure 1: Anatomy of an Eye [1]

The clinical test is carried out to confirm the presence of dry eye disease. As shown in Figure 2, clinical tests are mainly categorized into three categories [2-4]: tests based on quantity of tears produced, tests based on quality of tear film and other laboratory tests. Each of these categories comprises of different clinical tests. Schirmer test, tear meniscus assessment test and phenol red thread test are the tests carried out measuring the quantity of tears. Lipid layer pattern assessment, tear breakup time test, osmolarity of tear film and non-invasive breakup test are the tests carried out considering the quality of tear film.

The remaining tests such as meibomain gland functioning test, confocal microscopy, impression cytology and bio microscopic examinations are the other tests conducted in clinics. Though several clinical tests are available, techniques have been proposed in literature only for four of them and hence, only those four clinical tests have been computerized so far. Before we discuss DED detection techniques, below we briefly describe those four clinical tests for better understanding of their corresponding DED techniques. 


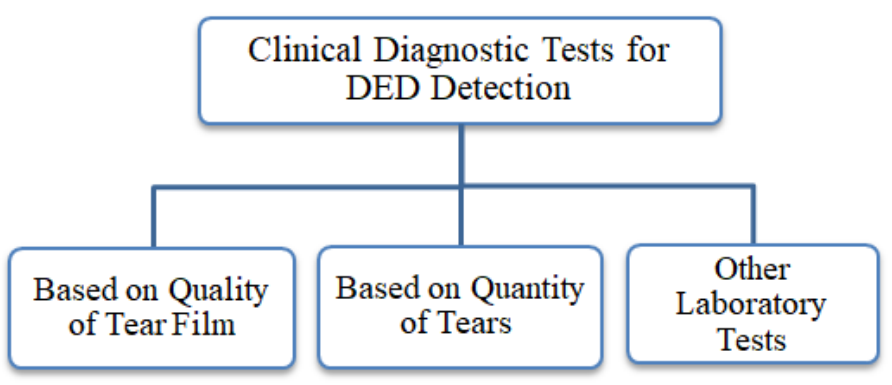

Figure 2: Clinical diagnostic tests for DED

\subsection{Tear film BreakUp Time (TBUT) Test}

TBUT test measures the stability of the tear film. In TBUT test $[2-5,9]$, sodium fluorescein drops are instilled in the eye and are spread over the entire area of eye by directing the patient to blink few times. Subsequently, the ophthalmologist observes the tear film using slit lamp and measures the time (in seconds) at which the dark spot/s first appears in the tear film.

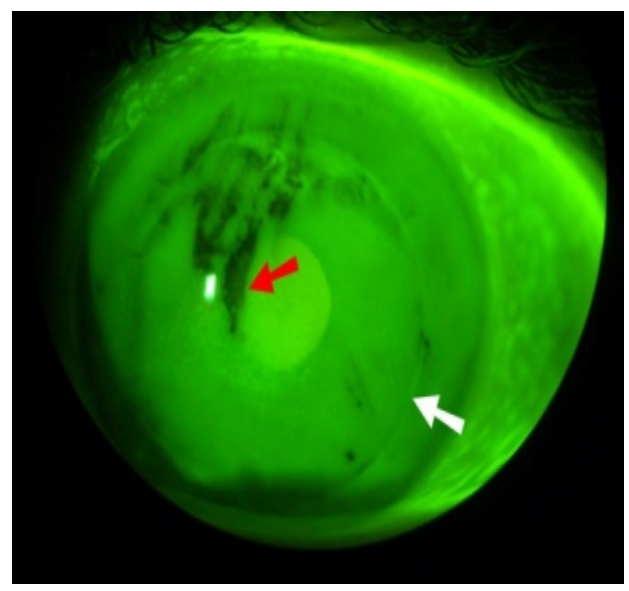

Figure 3: Tear film frame [22]

The appearance of the dark spot/s shows the instability of the tear film and thus, dry eye disease is detected. The time less than 5 seconds indicates dry eye, the time between 6 to 10 seconds indicates moderate dry eye and the time greater than 10 seconds indicates normal eye. Currently TBUT test is carried out manually by ophthalmologist or optometrist. The key shortcomings of manual TBUT test are it is time consuming and diagnosis done by it is subjective in nature as it depends on the observer. Figure 3 shows the breakup in tear film.

\subsection{Infrared Thermography Images}

In this test [3,9], DED is detected based on the temperature of tear film. The infrared thermal camera is used to capture the eye image from which the temperature of tear film is measured. This temperature is also known as Ocular Surface Temperature (OST). OST varies when tear film is unstable. The variations in OST are captured by infrared radiations and are analyzed with the help of colour coded image. The sample colour coded image is shown in Figure 4. The variation appearing in OST is one of the ways to detect tear film instability and thereby to detect DED. A normal healthy eye does not show any variation in temperature. The major issues related to this clinical test are it takes higher time in diagnosis of DED and is expensive as well.

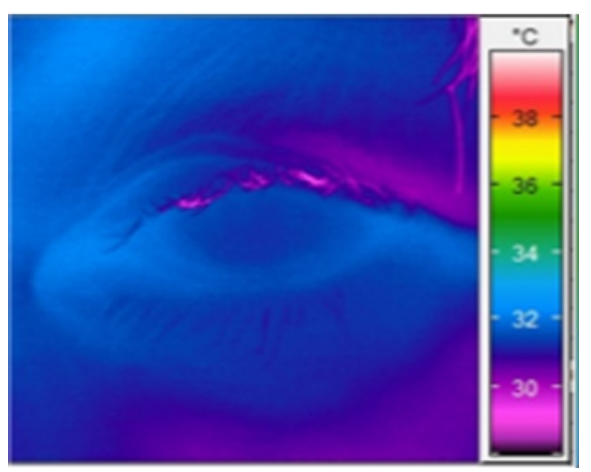

Figure 4: Thermal infrared image [25]

\subsection{Lipid Layer Interference Pattern}

Lipid layer is the first layer of the tear film. When light is projected over cornea, a pattern is formed over lipid layer [3, 89]. This pattern is captured using instrument called Tearscope Plus [23-24].

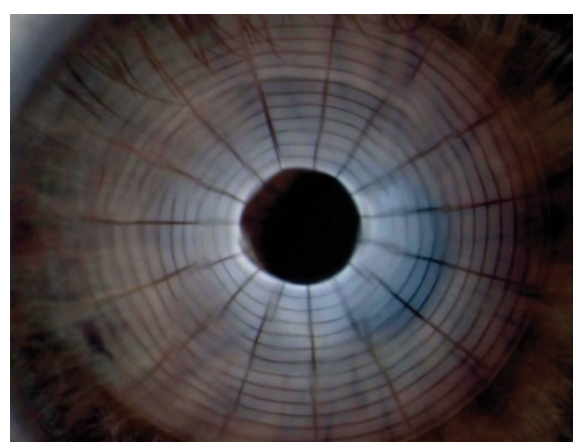

Figure 5: Lipid layer inference pattern [23]

As shown in Figure 5, it looks like a grid on lipid layer. The shape of pattern is classified into one of the following five categories: open meshwork, closed meshwork, wave, amorphous or colour fringe. These categories differ from each other with respect to colour and uniformity of lipid layer. The evaluation of lipid layer for non-uniformity and colour change assists in detection of DED.

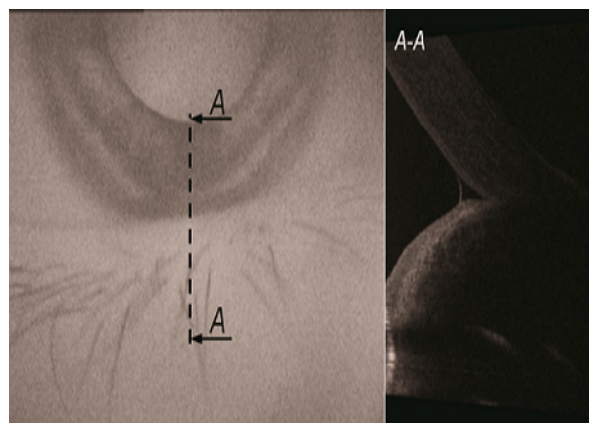

Figure 6: B-Scan of optical coherence tomography image [27]

\subsection{Tear Meniscus Assessment}

Tear meniscus $[2,6,9,27]$, also known as tear lake, is the collection of tears at the corners of eye. The measurement of its height, width and curves provide useful information for diagnosis of DED. Meniscus is measured manually using slit lamp or tearscope plus device by observing the quantity of tears in Tear 
Lake. If tear quantity is less than approximate $0.2 \mathrm{~mm}$, eye is considered as dry eye. Tear meniscus can also be measured from Optical Coherence Tomography (OCT) image. The sample optical coherence tomography image is shown in Figure 6.

\section{Computerized DED Detection Techniques}

Several DED detection techniques have been proposed over the years and are available in literature. As shown in Figure 7, we categorize them into three categories: techniques based on tear film stability, techniques based on blink rate detection and techniques based on amount of tears produced. These techniques aim to automatically identify the dry eye related area that indicates the presence or absence of DED.

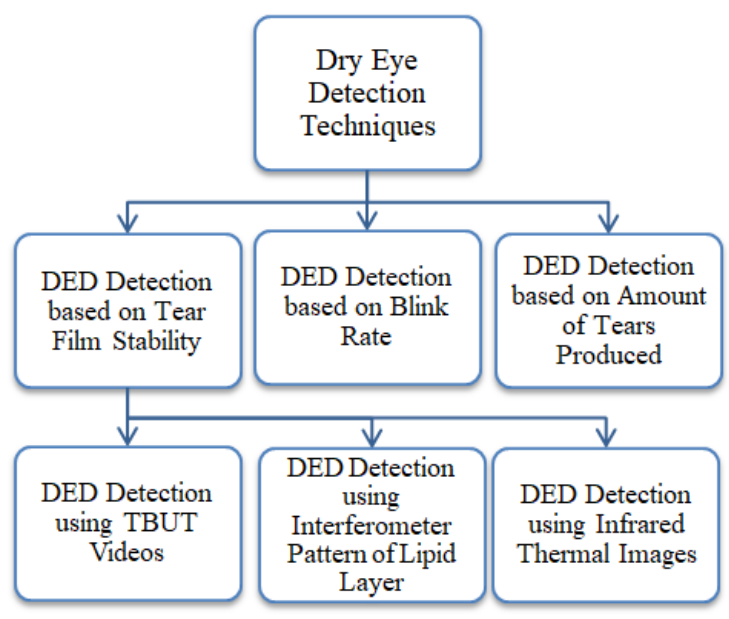

Figure 7: Classification of techniques for DED detection

The major steps involved in all these techniques are as follows: acquisition of eye image or eye video, pre-processing, feature extraction and classification.

\subsection{DED Detection Techniques based on Tear Film Stability}

Tear film resides on the outer layer of eye. It maintains the moisture of eye. It becomes instable due to evaporation of moisture from eye and gets ruptured. As shown in Figure 7, the techniques that diagnose DED based on tear film instability are further classified into three sub-categories: techniques based on breakup measurement, techniques that use interferometer pattern of lipid layer and techniques that use infrared thermal image to detect DED. We now discuss the various techniques that fall under these sub-categories.

\subsubsection{Techniques based on Breakup Measurement}

\section{Automatic Detection of DED}

The first automated DED detection technique was proposed in 2007 [15-16]. Input to this technique is an eye video that is captured using Eyescan device. We summarize the functioning of this technique in Figure 8. In this technique, input video is first divided into several frames. Then measurement areas are identified, where measurement area is the collection of frame/s that is/are captured when eye is completely open.

\begin{tabular}{|ll|}
\hline Begin & \\
1. & Select measurement areas \\
2. & For each frame in measurement areas \\
3. & Locate iris in the frame by creating edge map \\
4. & Select individual threshold value for iris, upper \\
eyelid and lower eyelid \\
5. Apply Random Sample Consensus (RANSAC) \\
algorithm to separate inliers(iris) and outliers \\
(eyelids) \\
6. Align all the above processed video frames to \\
7. Identify breakup spots \\
8. If breakup spots are present \\
9. $\quad$ Patient is suffering from dry eye disease \\
10. Else \\
11. \\
End
\end{tabular}

Figure 8: Major steps of automatic DED detection technique

In other words, it includes the frames that do not contain blink. Subsequently, iris is located in each frame of measurement area by creating edge map. This edge map is created using canny edge detection method. To eliminate illumination, to overcome blurring problem and to fit a circular mask, individual threshold values for iris, upper eyelid and lower eyelid are selected. All these video frames are then aligned to control the eye motion in video. Finally, breakup spots are identified by computing intensity value in each frame to know the presence of DED. If evolution curve of intensity values is created, it specifies the presence of dry eye disease.

\section{Automation of Tear Film Breakup Test}

In $[17,18]$, authors have proposed a technique for automatic detection of breakup spots. Input to this technique is an eye video. The major steps involved in this technique are depicted in Figure 9. During the first step, the measurement areas are detected from the input video. The key benefit of this technique is that unlike $[15,16]$, the measurement areas are detected automatically. They are detected based on symmetric difference in mean values of gray level of consecutive frames. High difference in mean values specifies the blink between two consecutive frames.

After locating the measurement areas, the Region of Interest (ROI) is located in each frame. The region of interest is iris on which the following three sub-steps are applied: identification of eye size, ROI alignment and ROI adjustment. Eye size is estimated using canny edge detection process and computing the size of circular mask. Next, eye movements in video are aligned by image registration process. Subsequently, iris is adjusted by cropping the background, eyelid and eyelashes portions that do not contain useful information.

The final step of this technique identifies the breakup spots using manually defined threshold value. For each frame in measurement areas, the histogram is created to calculate the threshold value of that frame. The largest value of gray level is 
considered as black and is used as threshold value. If the threshold value of frame is higher than the manually chosen threshold value, the breakup spots are present. If evolution curve of breakup spots is created, patient is suffering from dry eye disease.

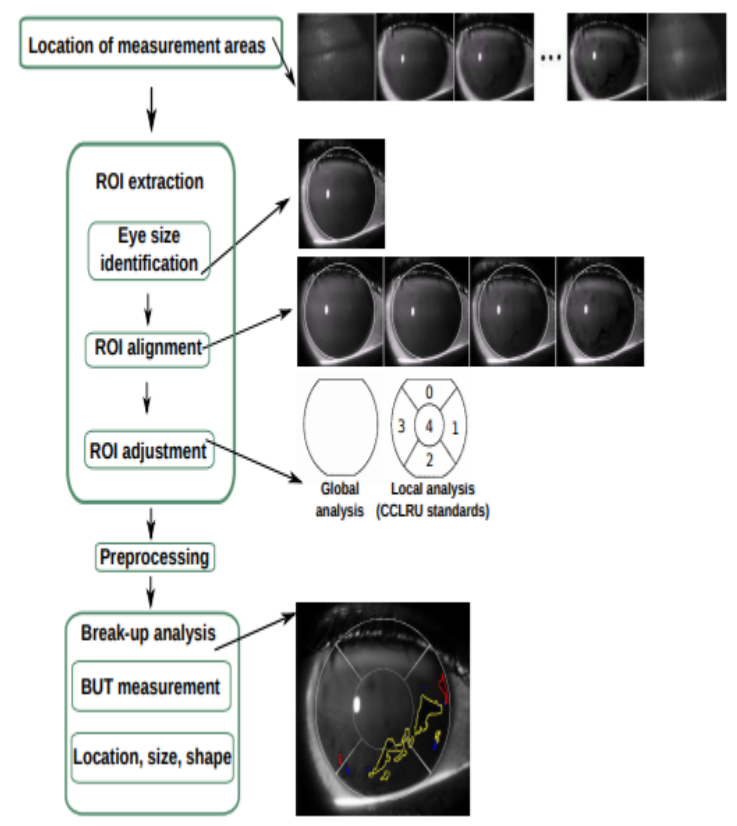

Figure 9: Flow of automation and analysis of TBUT [21]

The main drawback of this technique is that for every video in dataset, threshold value has to be selected manually due to difference in illumination condition and variation in quantity of fluorescein drops.

\section{Automation and Analysis of Tear Film Breakup Test}

In [19-21], authors have extended the previous technique. The authors observed that the previous technique only examines the breakup spots. However, size, shape and location of these breakup spots can assist ophthalmologist in further assessment of tear film. Particularly, they assist ophthalmologist to indicate tear film contamination as well as to detect breakup accurately. Hence, they modified the previous technique via adding one more step location, size and shape as the last step as shown in Figure 9.

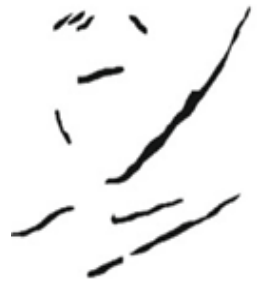

(a)

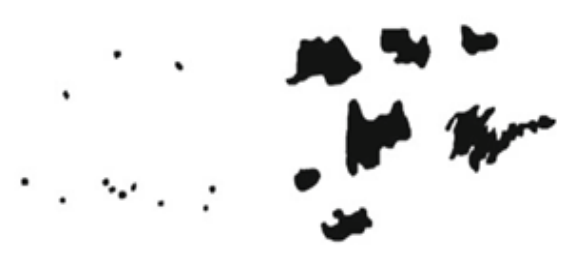

(b)

(c)
The initial steps of this technique are similar to previous technique [17-18]. After identification of breakup spots, rupture pattern is located in the last frame of video. Then two morphological operations, namely opening and closing, are applied to the last frame to smoothen it. Next, the features such as moment, area, roundness, axis ratio, convexity and solidity are calculated. They are then fed to decision tree classifier which gives output as one of the three classes: streak, dot or pool as shown in Figure 10. Irrespective of the output pattern, the output represents the presence of DED.

\section{Convolutional Neural Network based Screening of DED}

In [22], authors have proposed a technique based on Deep Convolutional Neural Network (DCNN) to detect tear film breakup time. Input to this technique is an eye video. The technique consists of two major phases: training phase and testing phase. During training phase, each video frame is segmented into small-size images of 96x96 pixels. Input to DCNN is 96x96 pixels images. DCNN is trained on segmented images to predict one of the five classes: eyelash, tear film breakup area, tear film nonbreakup area, sclera and eyelid. In testing phase, the input video is fragmented into frames for each second. The last frame (i.e. frame number 6) is given as the input to trained DCNN for identification of tear film breakup spot. Then probability map of breakup is created. Based on probability map, each of the frame numbers 1 to 5 is tested for appearance of breakup spot. If the breakup spot is present in the frame, dry eye disease is detected. The key limitation of this technique is that it limits dry eye detection up to 5 seconds ( 5 frames) and hence, is not able to identify further severity level of dry eye disease.

\subsubsection{Techniques based on Interference Pattern for Lipid Layer}

Two techniques have been proposed under this category. They are a Computer Aided System to Support Dry Eye Diagnosis based on tear film maps (CASDES) [23] and iDEAS [24]. Input to both these techniques is image captured using tearscope plus device. The image captured using tearscope device is typically categorized into one of the five categories: open meshwork, wave, closed meshwork, colour fringe and amorphous.

\section{A Computer Aided System to Support Dry Eye Diagnosis Based on Tear Film Maps (CASDES)}

In [23], a computer aided system to support dry eye diagnosis based on tear film maps is proposed. It is an automatic system that takes input in the form of image. From the input image, the CASDES system produces output in the form of tear film map. This tear film map contains the region that indicates dry eye. The three steps to produce tear film map are as follows. First, the iris is located in the input image by removing sclera and eyelid portion of the eye. Second, the image is converted from RGB to CIE-LAB colour space. The texture features are then calculated by generating gray level co-occurrence matrix. The colour and texture features together are fed to Support Vector Machine (SVM) classifier. The SVM classifier is trained to produce output as one of the following five classes: open meshwork, wave, closed meshwork, colour fringe or amorphous. The region growing algorithm is then applied on the output of SVM to find the dry eye region. The output image of region growing algorithm is known as tear film map. This image is also annotated manually by ophthalmologist to locate dry eye region. Third, the dry eye 
regions located by technique and ophthalmologist are compared to diagnose dry eye disease.

\section{IDEAS: A Web Based System for Dry Eye Assessment}

In [24], authors have presented a web based system for dry eye disease assessment. As shown in Figure 11, the system consists of four main parts: remote user interface, web application server, image processing module and data storage. The input to this system is interference pattern obtained using tearscope device. Output is in the form of tear film map that contains dry eye areas.

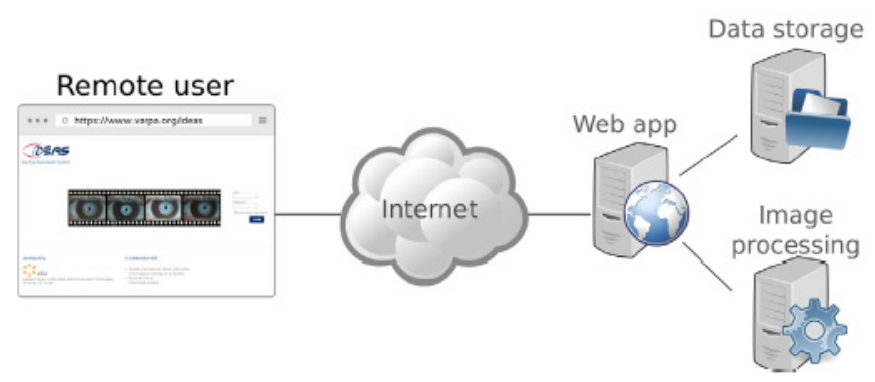

Figure 11: iDEAS system architecture [24]

The dry eye detection process is started by user via uploading patient's interference pattern. Once the interference pattern is uploaded, following steps are carried out by image processing module to detect dry eye. First, the iris is located in the interference pattern. Next, the low level colour and texture features such as mean, luminance of colour and gray levels are calculated. These features are then fed to SVM classifier. The SVM classifies the image into one of the five categories as mentioned in the previous technique. The region growing algorithm is then applied on the output of SVM to find the dry eye region. However, unlike previous technique, the dry eye region produced by system is not compared with any manually annotated dry eye region. Hence, dry eye related decision produced by the system is considered as the final decision. Data storage module of iDEAS system stores input patterns (tear film pattern of patients) as well as output patterns (labelled tear film pattern and classification results). iDEAS system is an easy to use system. Moreover, it can be used as a research tool as its data storage module has a large amount of patient's data. Additionally, it can be used over the internet with different underlying architectures.

\subsubsection{Techniques based on Thermal Infrared Images}

In literature, merely one technique is available that detects DED using thermal infrared images [25]. The input to this technique is an infrared image. The input image is converted from RGB to grayscale. Grayscale image is pre-processed using adaptive histogram method to enhance its contrast level. Next, the features are extracted from the image using radon transform method and High Order Spectra (HOS) method. The radon transform method converts $2 \mathrm{D}$ image into 1D data and the HOS method calculates the bispectral phase entropy function. The features extracted by both these method are then fed to different classifiers such as k-Nearest Neighbor (KNN), decision tree, Probabilistic Neural Network (PNN), SVM and Naive Bayes (NB). The result produced by this technique is binary that is either normal eye or dry eye. Authors observed that for left eye images,
PNN and KNN give better accuracy, whereas for right eye images, SVM gives better accuracy.

\subsection{DED Detection Technique Based on Blink Rate Detection}

Eye blink plays a major role in maintaining the moisture of eye. Use of electronic gadgets such as television, computer, mobile and laptop reduces eye blinks. Reduction in eye blinks indicates evaporation of moisture from eye. A DED detection technique based on blink rate has been proposed in literature for automatic measurement of blinks [26]. The monitoring system proposed by the authors detects blink rate using front camera of a tablet. The real time video having 30 to 35 frames per second is captured 18 using front camera. Then, the eye movements in video are digitized by extracting the pixels of pupil. Pixel variation in pupils of two consecutive video frames remains high if there is blink between two consecutive frames. Thus, high variation in pixels of pupils indicates blinks. If the detected blink rate is low, it alerts user about dry eye disease. The user reported with low blink rate is then checked manually through phenol red thread test to confirm dry eye disease. Based on this technique, authors also developed a mobile application which alerts users to take a break to give rest to eyes. This mobile application is based on Japan's guidelines for labor health management in a visual display terminal.

\subsection{DED Detection Techniques based on Amount of Tears} Produced

A technique named automatic dynamic tear meniscus measurement in optical coherence tomography has been proposed in literature [27]. It measures tear meniscus from optical coherence tomography images. Meniscus, also known as Tear Lake, is the collection of tears accumulated at the corner of eyelids. Meniscus's height and shape help to assess dry eye disease. Bscan image of OCT is considered as input to this technique. A tear meniscus parameter is evaluated from the image by extracting region of interest and generating a binary mask. The mask is then used to estimate the Eye-Eyelid Edge (EEE). A complement of binary mask is created for extracting the Tear Meniscus Profile (TMP). Information from both EEE and TMP are merged and is used to calculate area, depth and height of meniscus using edge based formula. If the values of area, depth and height fall under the predefined threshold values, the patient is identified with the presence of dry eye disease.

\section{Analysis and Discussion}

From our in-depth study of the existing computerized DED detection techniques, we have identified the following set of parameters to evaluate them rigorously: related clinical test, imaging modality, device used to capture image/video, image dimension, dataset, feature extraction method and classification approach. In this section, we first define these parameters and then present a comparative analysis of DED detection techniques based on identified parameters.

Related clinical test specifies the clinical test for which automation is done in the technique. Imaging modality specifies the type of input to the technique. It is either eye image or eye 


\section{A.H. Vyas et al. / Advances in Science, Technology and Engineering Systems Journal Vol. 5, No. 2, 748-756 (2020)}

video. Device used mentions the medical device used to capture input image/video. Image dimension specifies the image resolution in terms of pixels. Dataset represents the source of data and the number of images or videos used for the evaluation of the technique. There is no general dataset available for DED detection. The source of medical data is generally private or public hospitals. Feature extraction method specifies the method used to extract the features from image or video frames. Classification approach specifies the classification method used to detect the absence or presence of dry eye. In Table 1, we show the parametric evaluation of various DED detection techniques using these discovered parameters. Table 2 shows the summary of the existing DED detection techniques. Specifically, it summarizes key characteristics and limitations.

From a detailed comparison of various DED detection techniques in Table 1 and Table 2, it is observed that techniques differentiate in terms of image modality being used and tested with dissimilar database. Techniques based on fluorescein tear film video [15-22] identify appearance of dark spots and its time. The neural network based approach [22] has provided good accuracy for detection of breakup compared to others. The DED detection techniques based on interference pattern of lipid layer [23-24] detect predefined patterns and have potential to be used in clinical practice, as they provide a complete system with Graphical User Interface (GUI). Among the discussed imaging modality, thermal imaging [25] is useful image modality as it is non-invasive and does not come into direct contact with patient's eye. However, the TBUT based image modality is currently widely acceptable in clinical practice and hence, more automatized techniques should be developed. Perhaps, the main difficulty in developing new automated DED detection techniques lies in lack of public dataset. The dataset used in the mentioned techniques are private and limited in number of images/videos. Hence, a public dataset for all the image modalities would help to develop new techniques and develop computer aided diagnosis tool which can be used in clinical practice.

Table 1: Parametric evaluation of DED detection techniques

\begin{tabular}{|c|c|c|c|c|c|c|c|c|}
\hline Technique & $\begin{array}{c}\text { Related } \\
\text { clinical } \\
\text { test }\end{array}$ & $\begin{array}{l}\text { Imaging } \\
\text { modality }\end{array}$ & $\begin{array}{c}\text { Device } \\
\text { used to } \\
\text { capture } \\
\text { image/ } \\
\text { video } \\
\end{array}$ & $\begin{array}{c}\text { Image } \\
\text { dimension }\end{array}$ & Dataset & $\begin{array}{c}\text { Image/Video } \\
\text { processing } \\
\text { method used } \\
\text { to detect dry } \\
\text { eye }\end{array}$ & $\begin{array}{l}\text { Classificati } \\
\text { on } \\
\text { approach }\end{array}$ & $\begin{array}{l}\text { Evaluation } \\
\text { parameters }\end{array}$ \\
\hline $\begin{array}{l}\text { Automatic } \\
\text { detection of DED } \\
{[15]}\end{array}$ & $\begin{array}{l}\text { Tear film } \\
\text { breakup } \\
\text { time test }\end{array}$ & $\begin{array}{l}\text { Fluorescei } \\
\mathrm{n} \text { tear film } \\
\text { video }\end{array}$ & Eye scan & $\begin{array}{l}355 \text { x } 282 \\
\text { pixels }\end{array}$ & $\begin{array}{l}100 \text { videos from } \\
\text { Lions eye } \\
\text { institute, } \\
\text { Australia }\end{array}$ & $\begin{array}{l}\text { RANSAC } \\
\text { algorithm , } \\
\text { Segmentation } \\
\text { method }\end{array}$ & $\begin{array}{l}\text { Threshold } \\
\text { based }\end{array}$ & $\begin{array}{l}\text { Accuracy, } \\
\text { Standard } \\
\text { Deviation }\end{array}$ \\
\hline $\begin{array}{l}\text { Automation of } \\
\text { tear film breakup } \\
\text { test [17] }\end{array}$ & $\begin{array}{l}\text { Tear film } \\
\text { breakup } \\
\text { time test }\end{array}$ & $\begin{array}{l}\text { Fluorescei } \\
\mathrm{n} \text { tear film } \\
\text { video }\end{array}$ & $\begin{array}{l}\text { Topcon } \\
\text { DV3 }\end{array}$ & $\begin{array}{lll}1024 & \times 768 \\
\text { pixels } & & \end{array}$ & $\begin{array}{lr}20 \text { videos } & \text { from } \\
\text { university } & \text { of } \\
\text { Santiago } & \text { de } \\
\text { compostela } & \end{array}$ & $\begin{array}{l}\text { Morphological } \\
\text { operations for } \\
\text { rupture pattern }\end{array}$ & $\begin{array}{l}\text { Decision } \\
\text { tree } \\
\text { classifier }\end{array}$ & $\begin{array}{l}\text { Accuracy, } \\
\text { Breakup time } \\
\text { Measurement }\end{array}$ \\
\hline $\begin{array}{l}\text { Automation and } \\
\text { analysis of tear } \\
\text { film break up test } \\
{[19]}\end{array}$ & $\begin{array}{l}\text { Tear film } \\
\text { breakup } \\
\text { time test }\end{array}$ & $\begin{array}{l}\text { Fluorescei } \\
\mathrm{n} \text { tear film } \\
\text { video }\end{array}$ & $\begin{array}{l}\text { Topcon } \\
\text { DV3 }\end{array}$ & $\begin{array}{l}1024 \times 768 \\
\text { pixels }\end{array}$ & $\begin{array}{lr}18 \text { videos } & \text { from } \\
\text { university } & \text { of } \\
\text { Santiago } & \text { de } \\
\text { compostela } & \end{array}$ & $\begin{array}{l}\text { Histogram } \\
\text { based }\end{array}$ & $\begin{array}{l}\text { Threshold } \\
\text { based }\end{array}$ & $\begin{array}{l}\text { Accuracy, } \\
\text { Breakup time } \\
\text { Measurement }\end{array}$ \\
\hline $\begin{array}{l}\text { Convolutional } \\
\text { neural network } \\
\text { based screening of } \\
\text { DED [22] }\end{array}$ & $\begin{array}{l}\text { Tear film } \\
\text { breakup } \\
\text { time test }\end{array}$ & $\begin{array}{l}\text { Fluorescei } \\
\mathrm{n} \text { tear film } \\
\text { video }\end{array}$ & - & $\begin{array}{l}1024 \times 960 \\
\text { pixels }\end{array}$ & $\begin{array}{l}80 \text { videos from } \\
\text { Far Eastern } \\
\text { Memorial } \\
\text { Hospital }\end{array}$ & $\begin{array}{l}\text { Deep } \\
\text { convolutional } \\
\text { neural network }\end{array}$ & $\begin{array}{l}\text { Softmax } \\
\text { Classifier }\end{array}$ & $\begin{array}{l}\text { Accuracy, } \\
\text { Specificity, } \\
\text { Sensitivity, } \\
\text { Receiver } \\
\text { operating } \\
\text { characteristics } \\
\text { curve }\end{array}$ \\
\hline $\begin{array}{l}\text { A computer aided } \\
\text { system to support } \\
\text { Dry Eye diagnosis } \\
\text { based on tear film } \\
\text { maps [23] }\end{array}$ & $\begin{array}{l}\text { Lipid } \\
\text { Layer } \\
\text { pattern } \\
\text { Assessme } \\
\text { nt }\end{array}$ & $\begin{array}{l}\text { Lipid } \\
\text { layer } \\
\text { inference } \\
\text { pattern } \\
\text { images }\end{array}$ & $\begin{array}{l}\text { Tearscope } \\
\text { plus }\end{array}$ & $\begin{array}{l}1024 \times 768 \\
\text { pixels }\end{array}$ & $\begin{array}{l}50 \text { images from } \\
\text { VOPTICAL_R } \\
\text { dataset }\end{array}$ & $\begin{array}{l}\text { Feature vector } \\
\text { with image } \\
\text { segmentation }\end{array}$ & SVM & $\begin{array}{l}\text { Accuracy, } \\
\text { Specificity, } \\
\text { Sensitivity, } \\
\text { Precision }\end{array}$ \\
\hline $\begin{array}{l}\text { iDEAS: A web } \\
\text { based system for } \\
\text { dry } \\
\text { assessment [24] }\end{array}$ & $\begin{array}{l}\text { Lipid } \\
\text { Layer } \\
\text { pattern } \\
\text { Assessme } \\
\text { nt }\end{array}$ & $\begin{array}{l}\text { Lipid } \\
\text { layer } \\
\text { inference } \\
\text { pattern } \\
\text { images }\end{array}$ & $\begin{array}{l}\text { Tearscope } \\
\text { plus }\end{array}$ & - & $\begin{array}{l}128 \quad \text { images } \\
\text { from } \\
\text { VOPTICAL_I1 } \\
\text {-v2 }\end{array}$ & $\begin{array}{l}\text { Producing tear } \\
\text { film map using } \\
\text { seeded region } \\
\text { growing }\end{array}$ & SVM & $\begin{array}{l}\text { Accuracy, } \\
\text { Specificity, } \\
\text { Sensitivity, } \\
\text { Precision, } \\
\text { score }\end{array}$ \\
\hline $\begin{array}{l}\text { Technique based } \\
\text { on thermal } \\
\text { infrared images } \\
{[25]}\end{array}$ & $\begin{array}{l}\text { Assessing } \\
\text { thermal } \\
\text { image }\end{array}$ & $\begin{array}{l}\text { Thermal } \\
\text { imaging }\end{array}$ & $\begin{array}{l}\text { Variother } \\
m \text { head II }\end{array}$ & $\begin{array}{ll}442 \text { x } & 299 \\
\text { pixels } & \end{array}$ & $\begin{array}{l}500 \text { images } \\
\text { from Singapore } \\
\text { eye research } \\
\text { institute }\end{array}$ & $\begin{array}{l}\text { Radon } \\
\text { transform for } \\
\text { forming } \\
\text { feature vector }\end{array}$ & $\begin{array}{l}\text { SVM, KNN, } \\
\text { PNN }\end{array}$ & $\begin{array}{l}\text { Accuracy, } \\
\text { Specificity, } \\
\text { Sensitivity }\end{array}$ \\
\hline
\end{tabular}




\begin{tabular}{|l|l|l|l|l|l|l|l|l|}
\hline $\begin{array}{l}\text { DED technique } \\
\text { based on blink } \\
\text { rate detection [26] }\end{array}$ & - & Eye blinks & Tablet & $\begin{array}{l}\text { Low } \\
\text { resolution }\end{array}$ & 30 subjects & $\begin{array}{l}\text { Digitizing } \\
\text { eyeball } \\
\text { movements } \\
\text { using } \\
\text { processing } \\
\text { techniques }\end{array}$ & $\begin{array}{l}\text { Based } \\
\text { number } \\
\text { blinks } \\
\text { of }\end{array}$ \\
\hline $\begin{array}{l}\text { DED technique } \\
\text { based on amount } \\
\text { of tear produced } \\
\text { [27] }\end{array}$ & $\begin{array}{l}\text { Tear } \\
\text { meniscus } \\
\text { test }\end{array}$ & $\begin{array}{l}\text { OCT B } \\
\text { scan } \\
\text { images }\end{array}$ & $\begin{array}{l}\text { Spectral } \\
\text { OCT } \\
\text { instrument }\end{array}$ & $\begin{array}{l}900 \quad \mathrm{x} \quad 1009 \\
\text { pixels }\end{array}$ & $\begin{array}{l}\text { OCT B-Scan } \\
\text { from private } \\
\text { hospital }\end{array}$ & $\begin{array}{l}\text { Binary Generation } \\
\text { Gask }\end{array}$ & $\begin{array}{l}\text { Statistical } \\
\text { Analysis }\end{array}$ & $\begin{array}{l}\text { Tear Meniscus } \\
\text { Parameters }\end{array}$ \\
\hline
\end{tabular}

Table 2: Summary of DED Detection Techniques

\begin{tabular}{|c|c|c|}
\hline Technique & Key characteristics & Scope of improvement \\
\hline $\begin{array}{l}\text { Automatic detection of } \\
\text { DED [15] }\end{array}$ & $\begin{array}{l}\text { - Used RANSAC algorithm to locate iris in each } \\
\text { video frame } \\
\text { - Used least square optimization method to control } \\
\text { movement of iris } \\
\text { - }\end{array}$ & $\begin{array}{l}\text { - Identification of BUT sequences can be } \\
\text { automated } \\
\text { - Other features such as rupture pattern can } \\
\text { be identified and considered to increase } \\
\text { accuracy }\end{array}$ \\
\hline $\begin{array}{l}\text { Automation of tear film } \\
\text { breakup test [17] }\end{array}$ & $\begin{array}{l}\text { - Measurement area is located from the video } \\
\text { - Identifies the region of interest and aligns the } \\
\text { location of eye } \\
\text { - Classification based on rupture pattern }\end{array}$ & $\begin{array}{l}\text { - DED detection can be based on TBUT } \\
\text { measurement } \\
\text { - Accuracy can be further improved }\end{array}$ \\
\hline $\begin{array}{l}\text { Automation and analysis } \\
\text { of tear film break up test } \\
{[19]}\end{array}$ & $\begin{array}{l}\text { - } \\
\text { - Iden detection based on TBUT measurements } \\
\text { measure severity }\end{array}$ & $\begin{array}{l}\text { - Identification of evolution of breakup can } \\
\text { be considered to precisely detect DED } \\
\text { - A larger dataset should be used }\end{array}$ \\
\hline $\begin{array}{l}\text { Convolutional neural } \\
\text { network based screening } \\
\text { of DED [22] }\end{array}$ & $\begin{array}{l}\text { - } \text { Automatic detection of break up time through } \\
\text { Convolutional Neural Network (CNN) } \\
\text { - CNN Breakup time is proposed to detect time at } \\
\text { which first break up occurs } \\
\text { - Classifies into normal or dry eye } \\
\end{array}$ & $\begin{array}{l}\text { - Severity level of DED can be detected } \\
\text { - Processing time can be further reduced } \\
\text { - This technique can be further extended to } \\
\text { automatically diagnose DED }\end{array}$ \\
\hline $\begin{array}{l}\text { A computer aided system } \\
\text { to support dry eye } \\
\text { diagnosis based on tear } \\
\text { film maps [23] }\end{array}$ & $\begin{array}{l}\text { - Considers tear film lipid layer interference pattern } \\
\text { to detect DED } \\
\text { - Framework for diagnosing dry eye by observing the } \\
\text { tear film lipid layer interference patterns } \\
\text { - Also supports diagnosis of meibomain gland } \\
\text { dysfunction disease. }\end{array}$ & $\begin{array}{l}\text { - Can be extended to other imaging } \\
\text { modalities } \\
\text { - Accuracy can be further improved } \\
\text { - Time taken to produce tear film maps can } \\
\text { be reduced }\end{array}$ \\
\hline $\begin{array}{l}\text { iDEAS: A web based } \\
\text { system for dry eye } \\
\text { assessment [24] }\end{array}$ & $\begin{array}{l}\text { - Detection of dry eye through tear film map and tear } \\
\text { film classification } \\
\text { - Unbiased and repeatable results } \\
\text { - } \quad \text { Easy to use system for clinicians }\end{array}$ & $\begin{array}{l}\text { - } \text { Can be extended to other imaging } \\
\text { modalities } \\
\text { - Processing time can be further reduced }\end{array}$ \\
\hline $\begin{array}{l}\text { Technique based on } \\
\text { thermal infrared images } \\
{[25]}\end{array}$ & $\begin{array}{l}\text { - Considers thermogram image to detect DED } \\
\text { - Classifies into normal or dry eye }\end{array}$ & $\begin{array}{l}\text { - It can be further extended to diagnose } \\
\text { different stages } \\
\text { - Adequate storage space should be allotted } \\
\text { to store tear film maps }\end{array}$ \\
\hline $\begin{array}{l}\text { DED Technique based } \\
\text { on blink rate detection } \\
\text { [26] }\end{array}$ & $\begin{array}{l}\text { - } \\
\text { - } \text { Aletection of DED through blink rate } \\
\text { - } \text { Easy detection of blink through low resolution of } \\
\text { camera }\end{array}$ & $\begin{array}{l}\text { - Accuracy can be further improved } \\
\text { - Can be extended to other imaging } \\
\text { modalities }\end{array}$ \\
\hline $\begin{array}{l}\text { DED Technique based } \\
\text { on amount of tear } \\
\text { produced [27] }\end{array}$ & $\begin{array}{l}\text { - Considers OCT image to detect DED } \\
\text { - Detects tear meniscus using OCT images for } \\
\text { quantitative assessment of tears }\end{array}$ & $\begin{array}{l}\text { - Different scenarios such as post blink } \\
\text { measurement of tear meniscus should be } \\
\text { considered }\end{array}$ \\
\hline
\end{tabular}




\section{A. Vyas et al. / Advances in Science, Technology and Engineering Systems Journal Vol. 5, No. 2, 748-756 (2020)}

\section{Conclusion}

Dry eye disease is caused due to lack of moisture in eye. It is a common disease today that affects a significant population in the world. The burden of DED is expected to rise in future due to increasing use of visual devices. Thus, DED detection is important for effective medical treatment. In this paper, firstly, we have provided a systematic review on DED, its types and clinical diagnosis methods corresponding to which computerized DED detection techniques have been proposed in literature. Secondly, we have presented a detailed survey of various computerized DED detection techniques available in literature. Moreover, we have presented a parametric comparison of the discussed techniques. It is observed that only a few clinical methods have been automated and are able to show a good accuracy in DED detection. Therefore, there is an enormous research scope in the domain of DED detection by automating the current clinical tests. Our in-depth survey will help researchers to have a proper understanding of the existing image modality based computerized DED detection techniques. The future opportunities in the domain of DED detection include complete computerization of different clinical tests, so that the ophthalmologist can take advantage of the system for screening of DED.

\section{Conflict of Interest}

The authors declare no conflict of interest.

\section{References}

[1] J. N. Galveia, A. Travassos, F.A. Quadros, L.A. Cruz, "Computer Aided Diagnosis in Ophthalmology: Deep Learning Applications", Lecture Notes in Computational Vision and Biomechanics Classification in BioApps, vol. 26, 263-293, 2017. https://doi.org/10.1007/978-3-319-65981-7_10.

[2] H. Lin, S.C. Yiu, "Dry eye disease: A review of diagnostic approaches and treatments" ,Saudi Journal of Ophthalmology, vol. 28, 173-181, 2014. https://doi.org/10.1016/j.sjopt.2014.06.002.

[3] M.S. Zeev, D.D. Miller, R. Latkany, "Diagnosis of dry eye disease and emerging technologies", Clinical Ophthalmology, vol. 8, 581-590, 2014. https://doi.org/10.2147/opth.s45444.

[4] G.T. Vanley, I.H. Leopold, T.H. Gregg, "Interpretation of Tear Film Breakup", Archives of Ophthalmology, vol. 95, 445-448, 1977. https://doi.org/10.1001/archopht.1977.04450030087010.

[5] P.A. Rouen, M.L. White, "Dry Eye Disease", Home Healthcare Now. 36(2), 74-83, 2018. https://doi.org/10.1097/nhh.0000000000000652.

[6] S.P. Phadatare, M. Momin, P. Nighojkar, S. Askarkar, K.K. Singh, “A Comprehensive Review on Dry Eye Disease: Diagnosis, Medical Management, Recent Developments, and Future Challenges", Advances in Pharmaceutics.

[7] J.L. Gayton, "Etiology, prevalence, and treatment of dry eye disease", Clinical Ophthalmology, vol. 3, 405-412, 2009. https://doi.org/10.2147/opth.s5555.

[8] "Methodologies to Diagnose and Monitor Dry Eye Disease: Report of the Diagnostic Methodology Subcommittee of the International Dry Eye WorkShop", The Ocular Surface, vol. 5(2), 108-152, 2007. https://doi.org/10.1016/S1542-0124(12)70083-6.

[9] A.J. Bron, V.E. Evans, J.A. Smith, "Grading Of Corneal and Conjunctival Staining in the Context of Other Dry Eye Tests", Cornea, vol. 22, 640-650, 2003. https://doi.org/10.1097/00003226-200310000-00008.

[10] S.E. Moss, "Prevalence of and Risk Factors for Dry Eye Syndrome", Archives of Ophthalmology, vol. 118, 1264, 2000. https://doi.org/10.1001/archopht.118.9.1264.

[11] T.L. Simpson, P. Situ, L.W. Jones, D. Fonn, “ Dry Eye Symptoms Assessed by Four Questionnaires", Optometry and Vision Science, vol. 85(8), 692699, 2008. https://doi.org/ 10.1097/opx.0b013e318181ae36.

[12] F. Ozcura, S. Aydin, M.R. Helvaci, "Ocular Surface Disease Index for the Diagnosis of Dry Eye Syndrome", Ocular Immunology and Inflammation, vol. 15(5), 389-393, 2007. https://doi.org/10.1080/09273940701486803.
[13] Y. Guo, R. Peng, K. Feng, J. Hong, "Diagnostic Performance of McMonnies Questionnaire as a Screening Survey for Dry Eye: A Multicenter Analysis", Journal of Ophthalmology, vol. 2016, 1-6, 2016. https://doi.org/10.1155/2016/6210853.

[14] F. Amparo, D.A. Schaumberg, R. Dana, "Comparison of Two Questionnaires for Dry Eye Symptom Assessment”, Ophthalmology, vol. 122, 1498-1503, 2015. https://doi.org/10.1016/j.ophtha.2015.02.037.

[15] T. Yedidya, R. Hartley, J.P. Guillon, Y. Kanagasingam, "Automatic Dry Eye Detection", Medical Image Computing and Computer-Assisted Intervention - MICCAI 2007 Lecture Notes in Computer Science,792-799, 2007. https://doi.org/10.1007/978-3-540-75757-3_96.

[16] T. Yedidya, R. Hartley, J.P. Guillon, "Automatic Detection of Pre-ocular Tear Film Break-Up Sequence in Dry Eyes", 2008 Digital Image Computing: Techniques and Applications, 442-448, 2008. https://doi.org/10.1109/dicta.2008.70.

[17] L. Ramos, N. Barreira, A. Mosquera, M. Curras, H. Pena-Verdeal, M.J. Giraldez, M. Penedo, "Computational Approach for Measuring the Tear Film Break-Up Time in an Unsupervised Manner", Advanced Techniques for Knowledge Engineering and Innovative Applications, Communications in Computer and Information Science, vol 246, 254-267, 2013. https://doi.org/10.1007/978-3-642-42017-7_18.

[18] E. Cebreiro, L. Ramos, A. Mosquera, N. Barreira, M.F.G. Penedo, "Automation of the tear film break-up time test", Proceedings of the 4th International Symposium on Applied Sciences in Biomedical and Communication Technologies- Isabel11, 123, 1-5, 2011. https://doi.org/10.1145/2093698.2093821.

[19] B. Remeseiro, N. Barreira, L. Sanchez-Brea, L. Ramos, A. Mosquera, "Machine Learning Applied to Optometry Data", Advances in Biomedical Informatics, Intelligent Systems Reference Library, vol. 137, 123-160, 2017. https://doi.org/10.1007/978-3-319-67513-8_7.

[20] L. Ramos, N. Barreira, H. Pena-Verdeal, M. Giraldez, E. Yebra-Pimentel," Computational approach for tear film assessment based on break-up dynamics", Biosystems Engineering, vol. 138, 90-103, 2015. https://doi.org/10.1016/j.biosystemseng.2015.04.009.

[21] L. Ramos, N. Barreira, A. Mosquera, H. Pena-Verdeal, E. Yebra-Pimentel, "Break-Up Analysis of the Tear Film Based on Time, Location, Size and Shape of the Rupture Area", Image Analysis and Recognition in Lecture Notes in Computer Science, vol. 7950, 695-702, 2013. https://doi.org/10.1007/978-3-642-39094-4_79.

[22] T.-Y. Su, Z.-Y. Liu, D.-Y. Chen, "Tear Film Break-Up Time Measurement Using Deep Convolutional Neural Networks for Screening Dry Eye Disease", IEEE Sensors Journal, vol. 18, 6857-6862, 2018. https://doi.org/10.1109/jsen.2018.2850940.

[23] B. Remeseiro, A. Mosquera, M.G. Penedo, "CASDES: A Computer-Aided System to Support Dry Eye Diagnosis Based on Tear Film Maps", IEEE Journal of Biomedical and Health Informatics, vol. 20, 936-943, 2016. https://doi.org/10.1109/jbhi.2015.2419316.

[24] B. Remeseiro, N. Barreira, C. García-Resúa, M. Lira, M.J. Giraldez, E. Yebra-Pimentel, M. G. Penedo, "iDEAS: A web-based system for dry eye assessment", Computer Methods and Programs in Biomedicine, vol. 130, 186-197, 2016. . https://doi.org/10.1016/j.cmpb.2016.02.015.

[25] U.R. Acharya, J.H. Tan, J.E. Koh, V.K. Sudarshan, S. Yeo, C.L. Too, C.K. Chua, E.Y.K. Ng, L. Tong, "Automated diagnosis of dry eye using infrared thermography images", Infrared Physics \& Technology vol. 71, 263-271, 2015. . https://doi.org/10.1016/j.infrared.2015.04.007.

[26] E. Aihara, I. Torii, N. Ishii, "Development of Monitor System for Dry Eye Symptom", 2016 4th Intl Conf on Applied Computing and Information Technology $/ 3^{\text {rd }}$ Intl Conf on Computational Science/Intelligence and Applied Informatics/1st Intl Conf on Big Data, Cloud Computing, Data Science \& Engineering (ACIT-CSII-BCD), 241-246, 2016. https://doi.org/10.1109/acit-csii-bcd.2016.054.

[27] M.M. Bartuzel, D.H. Szczesna-Iskander, D.R. Iskander, "Automatic dynamic tear meniscus measurement in optical coherence tomography", Biomedical Optics Express, vol. 5(8), 2759-2768, 2014. https://doi.org/10.1364/boe.5.002759. 